\title{
Role of the microRNA-29 family in fibrotic skin diseases (Review)
}

\author{
DUYGU HARMANCI ${ }^{1}$, ERDOGAN PEKCAN ERKAN ${ }^{2}$, AYSE KOCAK $^{1}$ and GUL GUNER AKDOGAN ${ }^{3}$ \\ ${ }^{1}$ Department of Molecular Medicine, Graduate School of Health Sciences, Dokuz Eylul University, Izmir 35340, Turkey; \\ ${ }^{2}$ Department of Medical Genetics, Medicum, University of Helsinki, 00014 Helsinki, Finland; ${ }^{3}$ Department \\ of Medical Biochemistry, School of Medicine, Izmir University of Economics, Izmir 35330, Turkey
}

Received January 26, 2017; Accepted March 28, 2017

DOI: 10.3892/br.2017.900

\begin{abstract}
Fibrotic skin diseases are characterized by the accumulation of collagen. The hallmarks of fibrotic skin diseases are unbalanced fibroblast proliferation and differentiation, extracellular matrix production and transforming growth factor- $\beta$ signalling. Numerous studies have investigated the possibility that microRNAs (miRNAs or miRs) are involved in the pathogenesis of certain fibrotic diseases, including skin, heart, lung and liver diseases. miRNAs are a class of small non-coding RNAs, which modify gene expression by binding to target messenger RNA (mRNA) and blocking the translation or inducing the degradation of target mRNA. The biological relevance of miRNAs has been investigated in physiological and pathological conditions, and there is increasing evidence that the miR-29 family is associated with fibrotic diseases. The aim of the present review is to provide an up-to-date summary of current knowledge on the latest developments associated with the miR-29 family and fibrotic skin diseases.
\end{abstract}

\section{Contents}

1. Introduction

2. miRNAs

3. miR-29 family

4. miR-29 family in the pathogenesis of fibrotic skin diseases

5. Systemic sclerosis (SSc)

6. Graft-versus-host diseases (GvHD)

7. Keloids

8. Hypertrophic scars

9. miR-29 family as therapeutic target for fibrotic skin diseases

10. Conclusion

Correspondence to: Mrs. Duygu Harmanci, Department of Molecular Medicine, Graduate School of Health Sciences, Dokuz Eylul University, Health Campus, 1606 Mithatpasa Street, Izmir 35340, Turkey

E-mail: duyguharmanci@gmail.com

Key words: microRNA-29 family, skin, fibrotic skin diseases, function, pathogenesis

\section{Introduction}

Fibrotic skin disease is an umbrella term for a group of diseases, which is driven by inflammation, autoimmune mechanisms or environmental factors (1). Examples include all forms of scleroderma, graft-versus-host disease (GvHD), nephrogenic fibrosing dermopathy, mixed connective tissue disease, scleromyxedema, scleredema, eosinophilic fasciitis, keloids and hypertrophic scars. Fibrotic skin diseases have a significant negative effect on quality of life, specifically including issues with self-esteem.

A hallmark of fibrotic skin diseases is the involvement of the extracellular matrix (ECM), which occurs as a result of pathological and/or abnormal wound healing (1). Progression of fibrosis is a complex process and consists of immune, autoimmune and inflammatory mechanisms, as well as certain cytokines and chemical or physical factors $(1,2)$. Fibrotic skin diseases may be accompanied by psychological issues, as a result of reduced self-esteem. A small number of treatment options are useful; however, further therapeutic strategies are required for the management of skin fibrosis $(3,4)$. Accumulating clinical and experimental evidence indicate that the distribution of the balance of ECM remodelling is a key component (5).

Generally, tissue fibrosis occurs following injury and presents an abnormal wound healing process (5-7). Skin fibrosis progression may be followed by chronic inflammation, inflammation and intrinsic profibrotic changes in fibroblasts, and involves cytokines, growth factors and different cell types $(2,8)$. Endothelial cells, when damaged, release certain cytokines that activate immune cells. As a result, activated immune cells secrete fibrotic growth factors. Different cytokines and growth factors, such as transforming growth factor (TGF) $-\beta$, interleukin-4 (IL-4), interferon- $\gamma$ and tumour necrosis factor (TNF)- $\alpha$, connective tissue growth factor (CTGF) and platelet-derived growth factor (PDGF), participate in skin fibrosis. Growth factor actions lead to proliferation of fibroblasts and they differentiate into myofibroblasts during the fibrosis process $(9,10)$.

Following the discovery of microRNAs (miRNAs or miRs) in the early 2000s, studies have begun to discuss their roles in the physiological and pathological processes of diseases, including fibrosis (11). miRNAs are small non-coding RNAs (18-25 nucleotides) that block the translation or induce the degradation of target messenger RNA (mRNA) (12). miRNAs 
have different expression patterns and regulate various biological (such as cellular differentiation and cellular proliferation) and pathological (cancer and neurodegenerative disease) processes (11,13-16). Increasing evidence indicates that miRNAs participate in fibrotic disorders, including those of the skin, heart, kidney, liver and lung $(3,6,8)$. Previous studies have evaluated the possible roles of miRNAs in skin diseases $(3,4,8,17,18)$.

The miR-29 family includes miR-29a, miR-29b-1, miR-29b-2 and miR-29c. This family demonstrates anti-fibrotic activity and regulates a number of ECM proteins, including collagens, fibronectin, laminin, matrix metalloproteinase-2 (MMP-2), secreted protein acidic and rich in cysteine (19-25). Accumulating data suggest that the miR-29 family may be important in the homeostasis of the ECM.

In the present review, the role and function of the miR-29 family is summarized, with an emphasis on its role in the pathogenesis of fibrotic skin diseases, and its potential as a therapeutic molecule.

\section{2. miRNAs}

miRNAs are a class of non-coding RNAs that regulate mRNA processing at the post-transcriptional level (26). In 1993, Lee et al (27) discovered the first miRNA, lin-4 in Caenorhabditis elegans. In the early 2000s, Reinhart et al (28) identified the second miRNA, let-7 and, during the 2000s, more than a dozen miRNAs were identified in plant and animal species $(11,12,29)$. The chromosomal locations of miRNAs affect their expression and function. While the majority of mammalian miRNA genes are located in intronic regions, certain miRNA genes are located in exons, and $\sim 30 \%$ are located in intergenic regions $(13,30)$.

\section{3. miR-29 family}

The miR-29 family consists of four miRNAs: miR-29a, miR-29b-1, miR-29b-2 and miR-29c. miR-29a and miR-29b-1 are encoded by genes located on chromosome 7 (7q32.3), whereas miR-29b-2 and miR-29c are encoded on chromosome 1 (1q32.2). All three miRNAs share an identical 5 -nucleotide sequence in their seed region, which results in an overlap in the genes they target (22). Expression levels of miR-29 family members are regulated by multiple transcription factors, including Myc, nuclear factor (NF)- $\kappa$ B and Gli $(20,31)$.

The miR-29 family appears to exert a range of regulatory functions, controlling apoptosis $(32,33)$, proliferation $(34,35)$ and differentiation $(36,37)$. The antifibrotic activity of the miR-29 family is primarily based on its ability to target ECM genes. Various studies have independently demonstrated that the miR-29 family targets $>20$ ECM-associated genes, including collagen, elastin and integrin B1; therefore, the miR-29 family is a major target of this miRNA family $(22,24)$. miR-29 family members are actively involved in the fibrotic processes of various types of tissue, such as liver $(25,36,37)$, pulmonary $(19,38,39)$, cardiac $(40,41)$ and renal $(24,42)$, as well as in systemic sclerosis $(23,43-45)$, trabecular meshwork (9) and bone remodelling $(20,21,46)$.

Downregulation of different miR-29 family members has been reported in the liver $(25,37,47,48)$, lungs $(19,49)$, heart $(25,41)$, kidneys $(50,51)$ and skin (23) (Fig. 1).

\section{4. miR-29 family in the pathogenesis of fibrotic skin diseases}

The association between downregulated miR-29 expression levels and tissue fibrosis has been reported in different tissues, and it is not surprising that the miR-29 family is described as the 'master fibromiRNA' due to its pivotal role during the process of fibrosis (44). The roles of miR-29 individually in fibrotic skin diseases are discussed further in the following sections.

\section{Systemic sclerosis (SSc)}

SSc is an autoimmune disease that is closely associated with inflammation and fibrosis (7). The pathogenesis of this disease remains unclear and there is no effective treatment. The miR-29 family is predominantly evaluated in scleroderma, with regard to other fibrotic skin diseases. Maurer et al (23) demonstrated that miR-29a post transcriptionally regulates collagens in vitro and in vivo. The authors investigated primary skin fibroblasts and bleomycin-induced skin fibrosis in mice. It was determined that miR-29a was significantly downregulated in SSc fibroblasts and skin sections compared with healthy control samples. Furthermore, miR-29a expression was demonstrated to be decreased by major profibrotic mediators, TGF- $\beta$, PDGF subunit B and IL-4. Inhibition of TGF- $\beta$ signalling reregulates the miR-29 levels in SSc fibroblasts and bleomycin-induced mice (23). Kawashita et al (43) evaluated patients diagnosed with scleroderma and grouped all patients according to the subtypes of the disorder. It was determined that serum miR-29a was downregulated only in the scleroderma spectrum disorders. Furthermore, the authors demonstrated that collagen levels were upregulated in the SSc patients. Notably, a correlation between reduced miR-29a levels and increased right ventricular systolic pressure was determined in patients with SSc (43-45). Ciechomska et al (52) demonstrated that TGF- $\beta$-activated kinase-binding protein is a novel target of miR-29a, and it regulates TIMP metallopeptidase inhibitor 1, which is a key molecule for ECM deposition. Jafarinejad-Farsangi et al (53) determined that miR-29a possesses pro-apoptotic properties in addition to its anti-fibrotic effects. The protein expression of $\mathrm{B}$ cell lymphoma-2 (Bcl-2) family was altered by miR-29a in dermal fibroblasts from SSc patients and miR-29a induced apoptosis in this type of cell. Mcl-1, an anti-apoptotic BCL2 family member, is a target of miR-29b and is a member of the Bcl-2 family; therefore, the miR-29 family directly or indirectly affects Mcl-1 $(53,54)$. According to Takemoto et al (55) hair miR-29a levels in patients with scleroderma were markedly reduced when compared with the controls.

miR-29 is not the only miRNA that is involved in the pathogenesis of SSc. As discussed by Zhu et al (56), at least four other miRNAs are involved in SSc. Among these, miR-21 and miR-92a promote fibrosis, while miR-150 and miR-196a exert antifibrotic effects.

\section{Graft-versus-host diseases}

A common complication associated with allogeneic hematopoietic stem cell transplantation is the development of GvHD, which is observed in 50\% of recipient patients (57). 


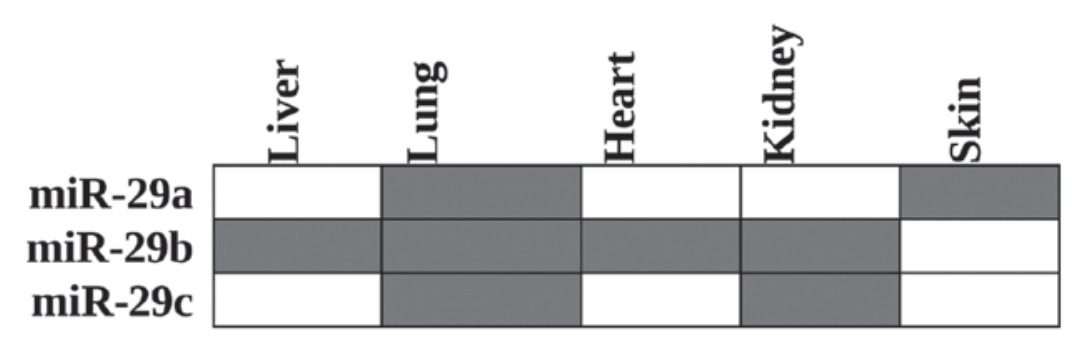

Figure 1. Downregulated miR-29 expression in different tissue samples, leading to fibrosis. The grey cells represent the downregulated members of the miR-29 family. miR, microRNA.

GvHD is an immune-mediated disease, which leads to morbidity and mortality. The major problem regarding GvHD prognosis and treatment depends only on clinical progression and, the unique method for establishing the GvHD prognosis is to determine any validated laboratory tests and results (58). Given the involvement of the skin and immune system in GvHD, the role of miRNAs in the pathogenesis of GvHD has been hypothesized. Xiao et al (59) provided supporting evidence for this hypothesis, and demonstrated that the plasma levels of miR-423, miR-199a-3p, miR-93* and miR-377 were significantly upregulated in patients with acute GvHD. In another study, Atarod and Dickinson (6) used Ingenuity Pathway Analysis to further investigate the interactions between the GvHD signalling pathway and miRNAs. The authors speculated that the miR-29 family targets IL- 6 and TNF- $\alpha$, and acts as downstream regulators of tissue damage (60). Notably, a large number of molecules have a role in GvHD pathogenesis, and various miRNAs are likely to exert regulatory roles in this process. In vivo models of GvHD, as well as clinical samples from GvHD patients may be utilized to identify the precise roles of the miR-29 family in this disease.

\section{Keloids}

Keloids are defined as benign dermal tumours. Keloids generally occur following an abnormal wound healing; however, the pathogenesis remains unclear (61). Zhang et al (62) determined that all miR-29 family members are expressed in keloid fibroblasts (KFs) and fresh skin biopsy specimens (obtained 24-48 h after surgery) and, in particular, miR-29a is highly expressed in KFs. The authors also evaluated the interaction of miR-29a and collagen type III $\alpha 1$ chain (COL $3 \alpha 1$ ) and demonstrated that miR-29a directly regulates enhancement of collagen production. Furthermore, in normal fibroblasts, miR-29a directly regulates collagen production via affecting TGF- $\beta$ expression (62). In another study, Liu et al (63) used microarray analysis for comparative miRNA profiling between keloid tissue and normal skin tissue samples. The authors identified 32 differentially expressed miRNAs, 23 of which were upregulated in keloid tissue samples. Notably, miR-21 was the most upregulated miRNA, whereas miR-203 was the most downregulated. Notably, none of the miR-29 family members were identified to be differentially expressed in the study. The most likely explanation for this observation is the stringent expression analysis, which excludes any miRNA that is not differentially expressed in all paired keloid-normal tissues (63).

\section{Hypertrophic scars}

Hypertrophic scars occur as a result of trauma, injury, surgery or burns. This type of scar is characterized by excessive deposition of the ECM. The incidence is more frequent when compared with keloids (64). To the best of our knowledge, the first analysis of differential miRNA expression in hypertrophic scars was performed by Ning et al (65), who demonstrated that miR-29b-1 expression was downregulated in hypertrophic scar tissue samples when compared with healthy control tissue samples. In another study, Guo et al (66) demonstrated that miR-29b treatment inhibited the TGF- $\beta 1 / \mathrm{Smad} / \mathrm{CTGF}$ signalling pathway in scalded model in mice. Zhou et al (67) reported that miR-21 and miR-200b are overexpressed in profibrotic hypertrophic scars, and speculated that these miRNAs are involved in the pathogenesis of hypertrophic scars through TGF- $\beta /$ Smad7/zinc finger E-box-binding homeobox 1 signalling. In a follow-up study, Li et al (68) reported that miR-21 inhibitor suppresses hypertrophic scar growth in a mouse model. Furthermore, downregulation of miR-143-3p is associated with COLI/III accumulation, and upregulation of CTGF (also termed CCN2) expression hypertrophic scars. $\mathrm{Mu}$ et al (69) demonstrated that forced overexpression of miR-143-3p inhibits proliferation of hypertrophic scar fibroblasts, and induces apoptosis via the Akt/mechanistic target of rapamycin (mTOR) signalling pathway. Taken together, these results indicate that multiple miRNAs are involved in the pathogenesis of hypertrophic scars, and their effects are performed predominantly via TGF- $\beta$-mediated signalling.

Notably, the interaction between the miR-29 family and TGF- $\beta$ has been revealed in cardiac and lung fibrosis $(19,41)$. Following treatment of TGF- $\beta 1$ on miR-29 knockdown IMR-90 cells, Cushing et al (19) demonstrated that certain genes were upregulated by TGF- $\beta$ and the authors observed that these genes predominantly consisted of miR-29-predicted targets. Decreased miR-29 expression levels lead to upregulation of Col3A1 and Col4A1. Furthermore, the stimulation of TGF- $\beta 1$ and knockdown of miR-29 exhibit the same behaviour in lung cells, and lead to upregulation of specific genes, including Col1A1, Col3A1 and Col1A2. In certain cases, TGF- $\beta 1$ stimulation may be insufficient compared with miR-29 inhibition, and this suggests that downregulation of miR-29 may facilitate TGF- $\beta$-mediated upregulation. Conversely, certain laminins, integrins, MMPs and ADAMs family are upregulated with downregulation of miR-29, but not with TGF- $\beta 1$ stimulation (19). Thus, these observations indicate that the miR-29 family regulates gene expression via TGF- $\beta$-dependent and -independent signalling pathways. 


\section{9. miR-29 family as therapeutic target for fibrotic skin diseases}

The effective treatment options have not been established in fibrotic skin diseases. Current treatment options are far from adequate; they only provide relief and assist patients by easing the side effects associated with main fibrotic disease $(3,8)$. Therefore, it is necessary to develop novel treatment options.

Recent evidence indicates that miRNAs may serve as therapeutic targets for certain fibrotic skin diseases. In particular, the miR-21 and miR-29 family have become prominent; however, considering that deregulated miR-21 expression is also associated with other pathological conditions, it is possible that negative effects associated with miR-21 deregulation may not be specific to fibrotic skin diseases $(4,6)$.

Gay et al (70) developed an miR-29 upregulator for scleroderma treatment and have submitted a patent application (http://www.google.ch/patents/US20110218233). Considering the anti-fibrotic properties of the miR-29 family, this approach is considered to be a suitable treatment option. In addition, synthetic short double-stranded oligonucleotide mimics and viral (lentiviral, adenoviral and adeno-associated viral) vectors may be used for treatment of fibrotic skin diseases in order to increase miR-29 expression $(3,4,6)$.

The possibility of restoring downregulated miR-29 expression via small molecules or synthetic oligonucleotides (miRNA mimics) has been investigated in different studies. In one example, Zhu et al (71) indicated that carvedilol, a non-selective $\beta$-adrenoreceptor antagonist, attenuates myocardial fibrosis in rats. The authors determined that carvedilol treatment exerts its effect via inhibition of Smad3 signalling and activation of miR-29b expression. Forced overexpression by miRNA mimics also exerted similar effects, which was demonstrated by a significant decrease in Col1A1, Col $3 \alpha 1$, and $\alpha$-smooth muscle actin expression levels in the two experimental conditions (71). In another example, van Rooij et al (41) suggested that restoring miRNA expression with synthetic oligonucleotides (miRNA mimics) or pharmacological inhibitors may be a useful approach to counteract the adverse effects of miR-29 downregulation in myocardial fibrosis. Thus, these suggest that restoring miR-29 expression may facilitate with reversing fibrosis.

\section{Conclusion}

Fibrosis is a complex process that involves excessive deposition and reorganization of the ECM, leading to epithelial-mesenchymal transition and TGF- $\beta$ activity. The activity of miRNAs is significant for fibrosis. Over the past decade, a numerous preclinical studies have revealed the role of miRNAs, particularly the miR-29 family, in fibrotic skin diseases. Briefly, downregulation of miR-29 expression levels leads to increased ECM protein expression levels. In addition, TGF- $\beta$ signalling is responsible for decreased miR-29 expression levels during the course of fibrosis. Therefore, targeting the miR-29 family and TGF- $\beta$ may be an effective strategy for the treatment of fibrosis. A substantial level experimental evidence has indicated that restoring downregulated miRNA expression with synthetic miRNA mimics may be a useful strategy to overcome fibrosis. However, such a strategy has certain technical (such as route of delivery and stability in circulation) and biological (targeted delivery, uptake rate and effective dose) limitations, which require further investigation using animal models and clinical trials.

\section{Acknowledgements}

The authors would like to thank Dr Dimitris Kletsas, Research Director of the Laboratory of Cell Proliferation \& Ageing (the Institute of Biology, National Centre for Scientific Research 'Demokritos', Athens, Greece) for his valuable contribution and comments.

\section{References}

1. Gardet A, Zheng TS and Viney JL: Genetic architecture of human fibrotic diseases: Disease risk and disease progression. Front Pharmacol 4: 159, 2013.

2. Vassiliadis E, Veidal SS, Barascuk N, Mullick JB, Clausen RE, Larsen L, Simonsen H, Larsen DV, Bay-Jensen AC, Segovia-Silvestre T, et al: Measurement of matrix metalloproteinase 9-mediated collagen type III degradation fragment as a marker of skin fibrosis. BMC Dermatol 11: 6, 2011.

3. Babalola O, Mamalis A, Lev-Tov H and Jagdeo J: The role of microRNAs in skin fibrosis. Arch Dermatol Res 305: 763-776, 2013.

4. Jinnin M: Various applications of microRNAs in skin diseases. J Dermatol Sci 74: 3-8, 2014.

5. Karsdal MA, Manon-Jensen T, Genovese F, Kristensen JH, Nielsen MJ, Sand JM, Hansen NU, Bay-Jensen AC, Bager CL, Krag A, et al: Novel insights into the function and dynamics of extracellular matrix in liver fibrosis. Am J Physiol Gastrointest Liver Physiol 308: G807-G830, 2015.

6. Jiang X, Tsitsiou E, Herrick SE and Lindsay MA: MicroRNAs and the regulation of fibrosis. FEBS J 277: 2015-2021, 2010.

7. Jinnin M: Mechanisms of skin fibrosis in systemic sclerosis. J Dermatol 37: 11-25, 2010.

8. Vettori S, Gay S and Distler O: Role of microRNAs in fibrosis. Open Rheumatol J 6: 130-139, 2012.

9. Villarreal G Jr, Oh DJ, Kang MH and Rhee DJ: Coordinated regulation of extracellular matrix synthesis by the microRNA-29 family in the trabecular meshwork. Invest Ophthalmol Vis Sci 52: 3391-3397, 2011

10. Wynn TA: Cellular and molecular mechanisms of fibrosis. J Pathol 214: 199-210, 2008.

11. Almeida MI, Reis RM and Calin GA: MicroRNA history: Discovery, recent applications, and next frontiers. Mutat Res 717: $1-8,2011$.

12. Bhaskaran M and Mohan M: MicroRNAs: History, biogenesis, and their evolving role in animal development and disease. Vet Pathol 51: 759-774, 2014.

13. Bartel DP: MicroRNAs: Target recognition and regulatory functions. Cell 136: 215-233, 2009.

14. Bushati N and Cohen SM: MicroRNA functions. Annu Rev Cell Dev Biol 23: 175-205, 2007.

15. Erkan EP, Breakefield XO and Saydam O: miRNA signature of schwannomas: Possible role(s) of 'tumor suppressor' miRNAs in benign tumors. Oncotarget 2: 265-270, 2011.

16. Senol O, Schaaij-Visser TB, Erkan EP, Dorfer C, Lewandrowski G, Pham TV, Piersma SR, Peerdeman SM, Ströbel T, Tannous B, et al: miR-200a-mediated suppression of non-muscle heavy chain IIb inhibits meningioma cell migration and tumor growth in vivo. Oncogene 34: 1790-1798, 2015.

17. Li Y, Huang J, Guo M and Zuo X: MicroRNAs Regulating Signaling Pathways: Potential Biomarkers in Systemic Sclerosis. Genomics Proteomics Bioinformatics 13: 234-241, 2015.

18. Noetel A, Kwiecinski M, Elfimova N, Huang J and Odenthal M: microRNA are Central Players in Anti- and Profibrotic Gene Regulation during Liver Fibrosis. Front Physiol 3: 49, 2012.

19. Cushing L, Kuang PP, Qian J, Shao F, Wu J,Little F, Thannickal VJ, Cardoso WV and Lü J: miR-29 is a major regulator of genes associated with pulmonary fibrosis. Am J Respir Cell Mol Biol 45: 287-294, 2011.

20. Kapinas K, Kessler C, Ricks T, Gronowicz G and Delany AM: miR-29 modulates Wnt signaling in human osteoblasts through a positive feedback loop. J Biol Chem 285: 25221-25231, 2010. 
21. Kapinas K, Kessler CB and Delany AM: miR-29 suppression of osteonectin in osteoblasts: Regulation during differentiation and by canonical Wnt signaling. J Cell Biochem 108: 216-224, 2009.

22. Kriegel AJ, Liu Y, Fang Y, Ding X and Liang M: The miR-29 family: Genomics, cell biology, and relevance to renal and cardiovascular injury. Physiol Genomics 44: 237-244, 2012.

23. Maurer B, Stanczyk J, Jüngel A, Akhmetshina A, Trenkmann M, Brock M, Kowal-Bielecka O, Gay RE, Michel BA, Distler JH, et al: MicroRNA-29, a key regulator of collagen expression in systemic sclerosis. Arthritis Rheum 62: 1733-1743, 2010.

24. Wang Y, Zhang X, Li H, Yu J and Ren X: The role of miRNA-29 family in cancer. Eur J Cell Biol 92: 123-128, 2013.

25. Zhang Y, Ghazwani M, Li J, Sun M, Stolz DB, He F, Fan J, Xie W and Li S: miR-29b inhibits collagen maturation in hepatic stellate cells through down-regulating the expression of HSP47 and lysyl oxidase. Biochem Biophys Res Commun 446: 940-944, 2014.

26. Ruvkun G: Molecular biology. Glimpses of a tiny RNA world. Science 294: 797-799, 2001

27. Lee RC, Feinbaum RL and Ambros V: The C.elegans heterochronic gene lin-4 encodes small RNAs with antisense complementarity to lin-14. Cell 75: 843-854, 1993.

28. Reinhart BJ, Slack FJ, Basson M, Pasquinelli AE, Bettinger JC, Rougvie AE, Horvitz HR and Ruvkun G: The 21-nucleotide let-7 RNA regulates developmental timing in Caenorhabditis elegans Nature 403: 901-906, 2000.

29. Carthew RW and Sontheimer EJ: Origins and mechanisms of miRNAs and siRNAs. Cell 136: 642-655, 2009.

30. Ameres SL and Zamore PD: Diversifying microRNA sequence and function. Nat Rev Mol Cell Biol 14: 475-488, 2013

31. Mott JL, Kurita S, Cazanave SC, Bronk SF, Werneburg NW and Fernandez-Zapico ME: Transcriptional suppression of mir-29b-1/mir-29a promoter by c-Myc, hedgehog, and NF-kappaB. J Cell Biochem 110: 1155-1164, 2010.

32. Kole AJ, Swahari V, Hammond SM and Deshmukh M: miR-29b is activated during neuronal maturation and targets $\mathrm{BH} 3$-only genes to restrict apoptosis. Genes Dev 25: 125-130, 2011.

33. Mott JL, Kobayashi S, Bronk SF and Gores GJ: mir-29 regulates Mcl-1 protein expression and apoptosis. Oncogene 26: 6133-6140, 2007.

34. Wei W, He HB, Zhang WY, Zhang HX, Bai JB, Liu HZ, Cao JH Chang KC, Li XY and Zhao SH: miR-29 targets Akt3 to reduce proliferation and facilitate differentiation of myoblasts in skeletal muscle development. Cell Death Dis 4: e668, 2013.

35. Zhu K, Liu L, Zhang J, Wang Y, Liang H, Fan G, Jiang Z Zhang CY, Chen X and Zhou G: MiR-29b suppresses the proliferation and migration of osteosarcoma cells by targeting CDK6. Protein Cell 7: 434-444, 2016.

36. Roderburg $\mathrm{C}$ and Luedde T: Circulating microRNAs as markers of liver inflammation, fibrosis and cancer. J Hepatol 61: 1434-1437, 2014

37. Roderburg C, Urban GW, Bettermann K, Vucur M, Zimmermann H, Schmidt S, Janssen J, Koppe C, Knolle P, Castoldi M, et al: Micro-RNA profiling reveals a role for miR-29 in human and murine liver fibrosis. Hepatology 53: 209-218, 2011

38. Cushing L, Kuang P and Lü J: The role of miR-29 in pulmonary fibrosis. Biochem Cell Biol 93: 109-118, 2015.

39. Yang T, Liang Y, Lin Q, Liu J, Luo F, Li X, Zhou H, Zhuang S and Zhang H: miR-29 mediates TGF 31 -induced extracellular matrix synthesis through activation of PI3K-AKT pathway in human lung fibroblasts. J Cell Biochem 114: 1336-1342, 2013.

40. Maegdefessel L, Azuma J and Tsao PS: MicroRNA-29b regulation of abdominal aortic aneurysm development. Trends Cardiovasc Med 24: 1-6, 2014.

41. van Rooij E, Sutherland LB, Thatcher JE, DiMaio JM, Naseem RH, Marshall WS, Hill JA and Olson EN: Dysregulation of microRNAs after myocardial infarction reveals a role of miR-29 in cardiac fibrosis. Proc Natl Acad Sci USA 105: 13027-13032, 2008.

42. Wang G, Kwan BC, Lai FM, Chow KM, Li PK and Szeto CC Urinary miR-21, miR-29, and miR-93: Novel biomarkers of fibrosis. Am J Nephrol 36: 412-418, 2012

43. Kawashita Y, Jinnin M, Makino T, Kajihara I, Makino K, Honda N, Masuguchi S, Fukushima S, Inoue Y and Ihn H: Circulating miR-29a levels in patients with scleroderma spectrum disorder. J Dermatol Sci 61: 67-69, 2011.

44. O'Reilly S: miRNA-29a in systemic sclerosis: A valid target. Autoimmunity 48: 511-512, 2015.

45. Peng WJ, Tao JH, Mei B, Chen B, Li BZ, Yang GJ, Zhang Q, Yao H, Wang BX, He Q, et al: MicroRNA-29: A potential therapeutic target for systemic sclerosis. Expert Opin Ther Targets 16: $875-879,2012$
46. Kapinas K and Delany AM: MicroRNA biogenesis and regulation of bone remodeling. Arthritis Res Ther 13: 220, 2011.

47. Knabel MK, Ramachandran K, Karhadkar S, Hwang HW, Creamer TJ, Chivukula RR, Sheikh F, Clark KR, Torbenson M, Montgomery RA, et al: Systemic Delivery of scAAV8-Encoded MiR-29a Ameliorates Hepatic Fibrosis in Carbon Tetrachloride-Treated Mice. PLoS One 10: e0124411, 2015.

48. Wang J, Chu ES, Chen HY, Man K, Go MY, Huang XR, Lan HY, Sung JJ and Yu J: microRNA-29b prevents liver fibrosis by attenuating hepatic stellate cell activation and inducing apoptosis through targeting PI3K/AKT pathway. Oncotarget 6: 7325-7338, 2015.

49. Xiao J, Meng XM, Huang XR, Chung AC, Feng YL, Hui DS, Yu CM, Sung JJ and Lan HY: miR-29 inhibits bleomycin-induced pulmonary fibrosis in mice. Mol Ther 20: 1251-1260, 2012.

50. Fang Y, Yu X, Liu Y, Kriegel AJ, Heng Y, Xu X, Liang M and Ding $X$ : miR-29c is downregulated in renal interstitial fibrosis in humans and rats and restored by HIF- $\alpha$ activation. Am J Physiol Renal Physiol 304: F1274-F1282, 2013.

51. Qin W, Chung AC, Huang XR, Meng XM, Hui DS, Yu CM, Sung JJ and Lan HY: TGF- $\beta /$ Smad3 signaling promotes renal fibrosis by inhibiting miR-29. J Am Soc Nephrol 22: 1462-1474, 2011.

52. Ciechomska M, O'Reilly S, Suwara M, Bogunia-Kubik K and van Laar JM: miR-29a reduces TIMP-1 production by dermal fibroblasts via targeting TGF- $\beta$ activated kinase 1 binding protein 1, implications for systemic sclerosis. PLoS One 9: e115596, 2014

53. Jafarinejad-Farsangi S, Farazmand A, Mahmoudi M, Gharibdoost F, Karimizadeh E, Noorbakhsh F, Faridani H and Jamshidi AR: MicroRNA-29a induces apoptosis via increasing the Bax:Bcl-2 ratio in dermal fibroblasts of patients with systemic sclerosis. Autoimmunity 48: 369-378, 2015.

54. Steele R, Mott JL and Ray RB: MBP-1 upregulates miR-29b that represses Mcl-1, collagens, and matrix-metalloproteinase- 2 in prostate cancer cells. Genes Cancer 1: 381-387, 2010.

55. Takemoto R, Jinnin M, Wang Z, Kudo H, Inoue K, Nakayama W, Ichihara A, Igata T, Kajihara I, Fukushima S, et al: Hair miR-29a levels are decreased in patients with scleroderma. Exp Dermatol 22: 832-833, 2013.

56. Zhu H, Luo $\mathrm{H}$ and Zuo X: MicroRNAs: Their involvement in fibrosis pathogenesis and use as diagnostic biomarkers in scleroderma. Exp Mol Med 45: e41, 2013.

57. Pavletic SZ and Fowler DH: Are we making progress in GVHD prophylaxis and treatment? Hematology Am Soc Hematol Educ Program 2012: 251-264, 2012.

58. Paczesny S, Raiker N, Brooks S and Mumaw C: Graft-versus-host disease biomarkers: Omics and personalized medicine. Int J Hematol 98: 275-292, 2013

59. Xiao B, Wang Y, Li W, Baker M, Guo J, Corbet K, Tsalik EL, Li QJ, Palmer SM, Woods CW, et al: Plasma microRNA signature as a noninvasive biomarker for acute graft-versus-host disease. Blood 122: 3365-3375, 2013

60. Atarod S and Dickinson AM: MicroRNAs: The Missing Link in the Biology of Graft-Versus-Host Disease? Front Immunol 4: 420, 2013.

61. Hahn JM, McFarland KL, Combs KA and Supp DM: Partial epithelial-mesenchymal transition in keloid scars: Regulation of keloid keratinocyte gene expression by transforming growth factor- $\beta 1$. Burns Trauma 4: 30, 2016.

62. Zhang GY, Wu LC, Liao T, Chen GC, Chen YH, Zhao YX, Chen SY, Wang AY, Lin K, Lin DM, et al: A novel regulatory function for miR-29a in keloid fibrogenesis. Clin Exp Dermatol 41: 341-345, 2016.

63. Liu Y, Yang D, Xiao Z and Zhang M: miRNA expression profiles in keloid tissue and corresponding normal skin tissue. Aesthetic Plast Surg 36: 193-201, 2012.

64. Lian $\mathrm{N}$ and Li T: Growth factor pathways in hypertrophic scars: Molecular pathogenesis and therapeutic implications. Biomed Pharmacother 84: 42-50, 2016.

65. Ning P, Liu DW, Mao YG, Peng Y, Lin ZW and Liu DM: Differential expression profile of microRNA between hyperplastic scar and normal skin]. Zhonghua Yi Xue Za Zhi 92: 692-694, 2012 (In Chinese).

66. Guo J, Lin Q, Shao Y, Rong L and Zhang D: miR-29b promotes skin wound healing and reduces excessive scar formation by inhibition of TGF- $\beta 1 / \mathrm{Smad} / \mathrm{CTGF}$ signaling pathway. Can J Physiol Pharmacol 95: 437-442, 2017.

67. Zhou R, Zhang Q, Zhang Y, Fu S and Wang C: Aberrant miR-21 and miR-200b expression and its pro-fibrotic potential in hypertrophic scars. Exp Cell Res 339: 360-366, 2015. 
68. Li G, Zhou R, Zhang Q, Jiang B, Wu Q and Wang C: Fibroproliferative effect of microRNA-21 in hypertrophic scar derived fibroblasts. Exp Cell Res 345: 93-99, 2016.

69. Mu S, Kang B, Zeng W, Sun Y and Yang F: MicroRNA-143-3p inhibits hyperplastic scar formation by targeting connective tissue growth factor $\mathrm{CTGF} / \mathrm{CCN} 2$ via the Akt/mTOR pathway. Mol Cell Biochem 416: 99-108, 2016.

70. Gay S, Distler O and Maurer B: Treatment of scleroderma US Patent US20110218233 A1. Filed September 4, 2009; issued September 8, 2011.
71. Zhu JN, Chen R, Fu YH, Lin QX, Huang S, Guo LL, Zhang MZ, Deng CY, Zou X, Zhong SL, et al: Smad3 inactivation and miR-29b upregulation mediate the effect of carvedilol on attenuating the acute myocardium infarction-induced myocardial fibrosis in rat. PLoS One 8: e75557, 2013. 